\title{
Impact of shoe size in a sample of elderly individuals
}

\author{
Daniel López-López ${ }^{1 *}$, Yésica Expósito-Casabella² ${ }^{2}$ Marta Losa-lglesias ${ }^{3}$, Ricardo Becerro de Bengoa-Vallejo4, \\ Jesús Luis Saleta-Canosa ${ }^{5}$, Francisco Alonso-Tajes ${ }^{6}$ \\ ${ }^{1}$ PhD. Health and Podiatry Research Unit, Department of Health Sciences, School of Nursing and Podiatry, Universidade da Coruña, Ferrol, Spain \\ 2Degree in Podiatry from Universidade da Coruña. Health and Podiatry Research Unit, Department of Health Sciences, School of Nursing and Podiatry, Universidade da Coruña, Ferrol, Spain \\ 3PhD. School of Health Sciences, Universidad Rey Juan Carlos, Madrid, Spain \\ ${ }^{4}$ DPM, PhD, DHL. Physiotherapy and Podiatry, School of Medicine, School of Nursing, Universidad Complutense de Madrid, Madrid, Spain \\ ${ }^{5} \mathrm{MD}$, PhD. Health and Podiatry Research Unit, Department of Health Sciences, School of Nursing and Podiatry, Universidade da Coruña, Ferrol, Spain \\ ${ }^{6}$ License in Podiatry. Health and Podiatry Research Unit, Department of Health Sciences, School of Nursing and Podiatry, Universidade da Coruña, Ferrol, Spain
}

Study conducted at the Facultade de Enfermaría e Podoloxía, Universidade da Coruña, Ferrol, España

Article received: $9 / 2 / 2014$ Accepted for publication: 10/21/2015

*Correspondence: Departamento de Ciencias da Saúde Facultade de Enfermaría e Podoloxía Address: Campus Universitario de Esteiro, $\mathrm{s} / \mathrm{n}$ Ferrol, España

Postal code: 15403 daniel.lopez.lopez@udc.es

\section{SUMMARY}

Introduction: The use of an improper shoe size is common in older people and is believed to have a detrimental effect on the quality of life related to foot health. The objective is to describe and compare, in a sample of participants, the impact of shoes that fit properly or improperly, as well as analyze the scores related to foot health and health overall.

Method: A sample of 64 participants, with a mean age of $75.3 \pm 7.9$ years, attended an outpatient center where self-report data was recorded, the measurements of the size of the feet and footwear were determined and the scores compared between the group that wears the correct size of shoes and another group of individuals who do not wear the correct size of shoes, using the Spanish version of the Foot Health Status Questionnaire.

Results: The group wearing an improper shoe size showed poorer quality of life regarding overall health and specifically foot health. Differences between groups were evaluated using a t-test for independent samples resulting statistically significant $(\mathrm{p}<0.05)$ for the dimension of pain, function, footwear, overall foot health, and social function.

Conclusion: Inadequate shoe size has a significant negative impact on quality of life related to foot health. The degree of negative impact seems to be associated with age, sex, and body mass index (BMI).

Keywords: foot, quality of life, foot deformities, shoes, aged, foot diseases.

\section{INTRODUCTION}

Shoes are a protective element for the health of the foot, and using a suitable size can reduce pressure, friction, and the impact generated by forces of the foot while walking, in addition to providing thermal and mechanical comfort. It therefore helps to improve people's functional capacity and posture. ${ }^{1}$

However, generalization and aesthetic demands sometimes lead to the use of an incorrect size adjustment that favors the appearance of disability, pain, functional limitations, fear of falls, and loss of postural stability, all with consequences for the autonomy and quality of life of people., ${ }^{2,3}$

Thus, when the shoes are too small, the pressure on the foot increases, and if the shoes are too large, they cause friction and the foot can slide inside the shoe. Both cases can lead to the development of ulcers, structural changes, and deformities, harming the person's health, their independence, and wellness. ${ }^{4,5}$

The increase in the prevalence rate of foot disorders, ranging from 71 to $87 \%$, changes that usually occur in this stage of life and are linked to walking adaptations where step width decreases and becomes more variable. As well as pace and cadence, the greater surface and time in which the two feet are in contact with the ground, are all elements that reveal the loss of independence, the vulnerability and lack of protection, as well as a need to provide tools to improve their autonomy, fall prevention, and health care to the elderly. ${ }^{6,7}$

In terms of foot structure, there is a morphological enlargement both in width and length, greater tolerance 
to pain, limitation of functional capacity that may favor the use of inadequate footwear and be a source of neuropathy, limitation of mobility while walking, changes in the distribution of foot pressure related to loss balance, all leading to disability, physical and cognitive impairment, negatively affecting the health of the elderly. ${ }^{8-10}$

Based on this background and considering that the population included in our study is in this stage of life, the detection of foot disorders and deformities, postural alterations, and other subjacent diseases are factors that should be taken into account in the planning of treatments and preventive activities aiming at improving the quality of life and well-being of the elderly. Therefore, the objective of our study was to describe and compare the scores obtained for foot health status and overall health status in a sample of elderly individuals wearing properfitting and badly-fitting shoes.

\section{Method}

\section{Study design and sample}

Descriptive observational study performed at a Health Center between September 2013 and February 2014. Sample selection was performed consecutively, the inclusion criteria being age greater than 65 years. The following were excluded from the study: immunosuppressed persons, previous trauma and history of foot surgery, neurological disorders, lack of autonomy/semiautonomy in daily activities, refusal to sign an informed consent form, and disability that would hinder comprehension and execution of instructions in the study.

\section{Procedure}

Measurements were performed by a single clinician, who first measured height, weight, and body mass index (BMI). Then, the participants completed the Foot Health Status Questionnaire (FHSQ), Spanish version. ${ }^{11}$ This self-administered health-related quality of life questionnaire is foot-specific and evaluates three sections. The first section evaluates pain, functionality, foot health, and footwear. A second dimension examines general health, physical function, social function, and vitality. The last section lists sociodemographic data including age, sex, and history of injury.

Once participants removed their socks and shoes, the same researcher evaluated and recorded the length and width of the feet with the Brannock Foot Meter. ${ }^{12}$

To do this, each participant stood barefoot and relaxed, with their feet slightly apart and with the weight evenly distributed between both feet. Then, with the help of the investigator, they inserted the foot into the device, from the most posterior part of the calcaneus to the tip of the longest finger. Note that the longest finger was not necessarily the first finger. ${ }^{13}$ The same protocol was established for the other foot and also to measure the shoe.

The score obtained for the length, the width of each foot and the shoe were made with a comparison between the two feet. The differences were evaluated by subtracting the length of the foot from the length of the shoe, and the same protocol was used to obtain a score for width of the foot and shoe. The correct size is when the size of the shoe minus size of the foot is equal to zero. If the result is $>0$, the shoe is too large, while $<0$ indicates that the shoe is too small for the actual foot requirement. ${ }^{13}$

\section{Sample size}

In order to detect a difference of at least 21 points in the Spanish version of the FHSQ, which is clinically relevant, among the groups studied, and knowing that the standard deviation $(\mathrm{SD})$ in this scale in people with proper-fitting shoes is around 29 points, ${ }^{14}$ for a bilateral hypothesis, an alpha risk of $5 \%$ and a statistical power of $80 \%$, it is necessary to study 31 subjects in each group ( $\mathrm{n}=62)$.

\section{Ethical considerations}

The research was approved by the Research and Ethics Committee of Universidade da Coruña (Spain) under file number CE 02/2014. All volunteers gave their informed written consent prior to being included in the study and ethical standards of human experimentation were preserved according to the Declaration of Helsinki (World Medical Assembly) and the European Council of Convention on Human Rights and Biomedicine, the Unesco Universal Declaration on the Human Genome and Human Rights and the appropriate national agencies or institutions.

\section{Statistical analysis}

A descriptive analysis of the variables included in the study was performed. The qualitative variables are presented as absolute values and percentages. Quantitative variables are described as mean, median, $\mathrm{SD}$, maximum, and minimum values. We performed a chi-square test for the comparison of qualitative variables and a Student's t-test for the comparison of means. Finally, to determine which variables were related to the scores in each of the dimensions of the FHSQ, a multivariate analysis of multiple linear regression was performed, in which the dependent variable was the score of each of the dimensions. As independent variables, all the variables that showed a statistically significant relationship with that dimension in the univariate analysis $(\mathrm{p}<0.05)$ were introduced into the model. 
We used the Statistical Package for the Social Sciences (SPSS) for data analysis. ${ }^{19}$ As for the scores of quality of life related to foot health, they were obtained based on the Foot Health Status Questionnaire version 1.03.

\section{RESULTS}

A total of 62 people aged over 65 years completed the study. They comprised 29 (46.8\%) men and 33 (53.2\%) women aged between 65 and 96 years.

Table 1 shows the clinical characteristics (domains of the FHSQ questionnaire) and sociodemographic characteristics of the study participants. As can be seen, as a whole, these are overweight individuals $\left(\mathrm{BMI}=27,5 \mathrm{~kg} / \mathrm{m}^{2}\right)$.

TABLE 1 Sociodemographic and clinical characteristics of the sample.

\begin{tabular}{lllll} 
& Mean (SD) & Median & Maximum & Minimum \\
\hline Pain & $81.5(18.7)$ & 87.5 & 100 & 23.13 \\
\hline Function & $87.6(17.8)$ & 93.8 & 100 & 12.5 \\
\hline Shoe & $58.3(29.2)$ & 66.7 & 100 & 0 \\
\hline $\begin{array}{l}\text { General foot } \\
\text { health }\end{array}$ & $59.2(26.6)$ & 60 & 100 & 0 \\
\hline Overall health & $56.6(16.4)$ & 60 & 90 & 20 \\
\hline $\begin{array}{l}\text { Physical } \\
\text { function }\end{array}$ & $76.9(21.3)$ & 88.9 & 100 & 27.8 \\
\hline Social function & $86.9(17.3)$ & 100 & 100 & 37.5 \\
\hline Vitality & $63.5(28.9)$ & 75 & 100 & 0 \\
\hline Age & $75.3(7.9)$ & 76 & 96 & 65 \\
\hline Weight $(\mathrm{kg})$ & $73.9(11.3)$ & 75 & 105 & 48 \\
\hline Height $(\mathrm{cm})$ & $164.1(7.6)$ & 165 & 183 & 150 \\
\hline BMI $\left(\mathrm{kg} / \mathrm{m}^{2}\right)$ & $27.5(4)$ & 26.9 & 38.57 & 19.98 \\
\hline BMI: body mass index. & & & &
\end{tabular}

Regarding the comparison of the scores obtained in the Spanish version of the FHSQ, sample results are displayed in Figure 1. These scores were higher in the group of participants wearing proper-fitting shoes both in the first section of the questionnaire, which evaluates the quality of life specifically related to foot health, and in the second section, which evaluates health status in general.

The differences between the two groups were statistically significant $(p<0.05)$ for the dimensions of the questionnaire assessing pain, foot function, general foot health, and social function.

Tables 2 and 3 show the variables that were significantly associated with the dimensions of the FHSQ questionnaire, namely type of shoe, sex, BMI, and age, the latter being solely associated with the social function dimension.

Since in the univariate analysis a relationship was found in the dimensions of the FHSQ questionnaire pain, function, general foot health, and social function, with different variables, an adjustment was made using a multiple linear regression model (Table 4).

\section{Discussion}

The main objective of this study was to determine if inadequate footwear, i.e. shoes that do not fit properly, has an impact on the quality of life of the elderly.

Using shoes the right size is paramount, especially for patients who are at high risk of developing foot ulcers. ${ }^{15}$ However, judging by the results of the few studies done on this subject, the choice of appropriate footwear is not as obvious as it seems, since only 25.5 to $28 \%$ of older people wear proper-fitting shoes. ${ }^{16,17}$

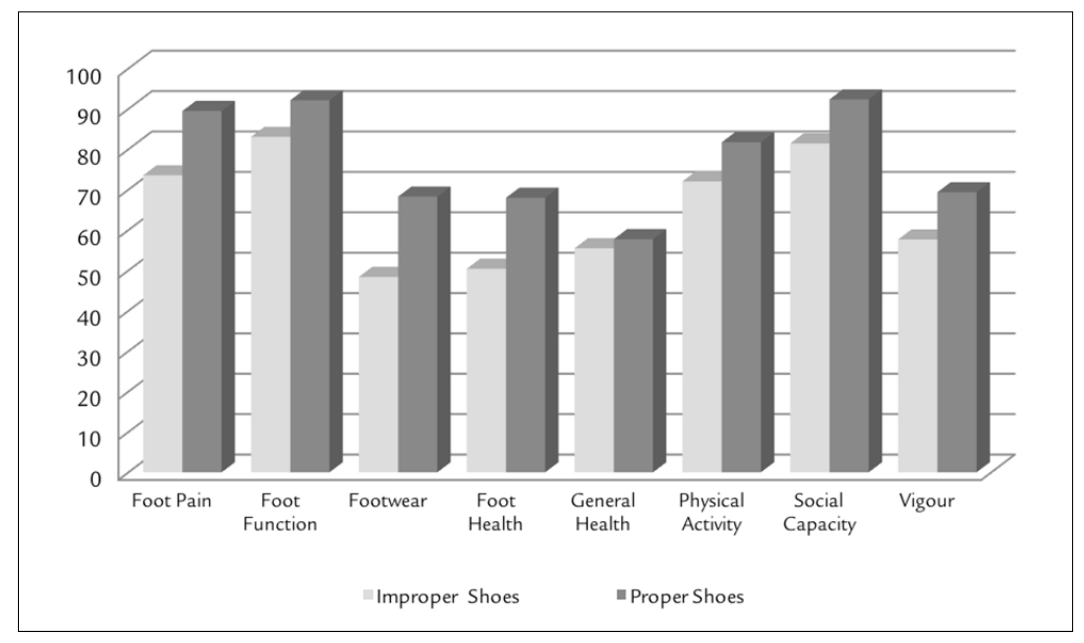

FIGURE 1 Foot Health Status Questionnaire mean scores. 
TABLE 2 Variables significantly associated with the dimensions of the FHSQ questionnaire.

\begin{tabular}{|c|c|c|c|c|c|c|}
\hline & \multicolumn{3}{|l|}{ Type of shoe } & \multicolumn{3}{|l|}{ Sex } \\
\hline & Proper-fitting & Badly-fitting & & Male & Female & \\
\hline & Median (SD) & Median (SD) & $\mathbf{p}$ & Median (SD) & Median (SD) & $\mathbf{p}$ \\
\hline Pain & $89.5(12.6)$ & $73.5(20.6)$ & 0.001 & $91.6(13)$ & $72.7(18.6)$ & 0.000 \\
\hline Foot function & $92.1(13.3)$ & $83.1(20.6)$ & 0.043 & $95(8.4)$ & $81.1(21.1)$ & 0.001 \\
\hline General foot condition & $68(24)$ & $50.4(26.7)$ & 0.008 & $73(22.6)$ & $47(24.1)$ & 0.000 \\
\hline Social function & $92.3(14.3)$ & $81.5(18.5)$ & 0.012 & $93.5(11.4)$ & $81.1(19.5)$ & 0.003 \\
\hline
\end{tabular}

\section{TABLE 3 Variables significantly associated with the dimensions of the FHSQ questionnaire.}

\begin{tabular}{|c|c|c|c|c|c|c|c|}
\hline & B & Standard error & Beta & $\mathbf{T}$ & Sigma & $95 \mathrm{Cl}$ for $\mathrm{B}$ & \\
\hline & & & & & & Lower limit & Upper limit \\
\hline Pain & 99.9 & 23 & & 4.3 & 0.000 & 53.9 & 146.1 \\
\hline \multicolumn{8}{|l|}{ (Constant) } \\
\hline Age & -0.2 & 0.3 & -0.1 & -0.8 & 0.424 & -0.9 & 0.4 \\
\hline (Constant) & 121.9 & 16 & & 7.6 & 0.000 & 89.9 & 154 \\
\hline $\operatorname{BMI}\left(\mathrm{kg} / \mathrm{m}^{2}\right)$ & -1.5 & 0.6 & -0.3 & -2.6 & 0.013 & -2.6 & -0.3 \\
\hline \multicolumn{8}{|l|}{ Foot function } \\
\hline (Constant) & 113.6 & 21.7 & & 5.2 & 0.000 & 70.2 & 157.1 \\
\hline Age & -0.3 & 0.3 & -0.2 & -1.2 & 0.233 & -0.9 & 0.2 \\
\hline (Constant) & 149.1 & 13.9 & & 10.8 & 0.000 & 121.3 & 176.8 \\
\hline BMI $\left(\mathrm{kg} / \mathrm{m}^{2}\right)$ & -2.2 & 0.5 & -0.5 & -4.5 & 0.000 & -3.2 & -1.2 \\
\hline \multicolumn{8}{|c|}{ General foot condition } \\
\hline (Constant) & 98.2 & 32.6 & & 3 & 0.004 & 33 & 163.4 \\
\hline Age & -0.5 & 0.4 & -0.2 & -1.2 & 0.233 & -1.4 & 0.3 \\
\hline (Constant) & 122.8 & 22.5 & & 5.5 & 0.000 & 77.8 & 167.9 \\
\hline BMI $\left(\mathrm{kg} / \mathrm{m}^{2}\right)$ & -2.3 & 0.8 & -0.3 & -2.9 & 0.006 & -3.9 & -0.7 \\
\hline \multicolumn{8}{|c|}{ Social function } \\
\hline (Constant) & 140.6 & 20.3 & & 6.9 & 0.000 & 100.1 & 181.1 \\
\hline Age & -0.7 & 0.3 & -0.3 & -2.7 & 0.010 & -1.2 & -0.2 \\
\hline (Constant) & 121 & 14.9 & & 8.1 & 0.000 & 91.2 & 150.9 \\
\hline $\mathrm{BMI}\left(\mathrm{kg} / \mathrm{m}^{2}\right)$ & -1.2 & 0.5 & -0.3 & -2.3 & 0.024 & -2.3 & -0.2 \\
\hline
\end{tabular}

TABLE 4 Multivariate analysis of the relationship of the dimensions of the FHSQ questionnaire with different variables.

\begin{tabular}{|c|c|c|c|c|c|c|c|}
\hline & & B & Standard error & Beta & Sigma & $95 \mathrm{Cl}$ for $\mathrm{B}$ & \\
\hline & & & & & & Lower limit & Upper limit \\
\hline Pain & (Constant) & 103.4 & 14.6 & & 0.000 & 74.1 & 132.7 \\
\hline & Type of shoe (Proper-fitting) & -9.7 & 4.2 & -0.3 & 0.024 & -18.2 & -1.3 \\
\hline & $\operatorname{BMI}\left(\mathrm{kg} / \mathrm{m}^{2}\right)$ & -0.9 & 0.5 & -0.2 & 0.098 & -1.9 & 0.2 \\
\hline & Sex (female) & 13.9 & 4.2 & 0.4 & 0.002 & 5.4 & 22.4 \\
\hline Foot function & (Constant) & 136.8 & 14.1 & & 0.000 & 108.6 & 165 \\
\hline & $\mathrm{BMI}\left(\mathrm{kg} / \mathrm{m}^{2}\right)$ & -1.9 & 0.5 & -0.4 & 0.000 & -2.9 & -0.9 \\
\hline & Type of shoe (proper-fitting) & -2.9 & 4 & -0.1 & 0.474 & -11 & 5.2 \\
\hline & Sex (female) & 9.6 & 4.1 & 0.3 & 0.022 & 1.5 & 17.8 \\
\hline
\end{tabular}


TABLE 4 (Cont.) Multivariate analysis of the relationship of the dimensions of the FHSQ questionnaire with different variables.

\begin{tabular}{|c|c|c|c|c|c|c|c|}
\hline \multirow{4}{*}{$\begin{array}{l}\text { General foot } \\
\text { condition }\end{array}$} & (Constant) & 96.6 & 21.5 & & 0.000 & 53.6 & 139.5 \\
\hline & $\mathrm{BMI}\left(\mathrm{kg} / \mathrm{m}^{2}\right)$ & -1.6 & 0.7 & -0.2 & 0.041 & -3.1 & -0.1 \\
\hline & Sex (female) & 20.4 & 6.2 & 0.4 & 0.002 & 7.9 & 32.8 \\
\hline & Type of shoe (proper-fitting) & -8.1 & 6.2 & -0.2 & 0.195 & -20.4 & 4.3 \\
\hline \multirow[t]{5}{*}{ Social function } & (Constant) & 170.2 & 24.4 & & 0.000 & 121.3 & 219 \\
\hline & BMI $\left(\mathrm{kg} / \mathrm{m}^{2}\right)$ & -0.9 & 0.5 & -0.2 & 0.050 & -2 & 0.0 \\
\hline & Type of shoe (proper-fitting) & -7.7 & 4.1 & -0.2 & 0.064 & -15.8 & 0.5 \\
\hline & Sex (female) & 7 & 4.1 & 0.2 & 0.097 & -1.3 & 15.2 \\
\hline & Age & -0.7 & 0.2 & -0.3 & 0.004 & -1.2 & -0.3 \\
\hline
\end{tabular}

The results of our study confirm that people who use badly-fitting shoes have more pain in their feet than those who use proper-fitting shoes. The variables that play an independent effect in this dimension (pain) were the type of footwear and sex, after adjustment in a multivariate model for the variables type of footwear, BMI, and sex. In this sense, being male, compared with the reference category (female), increases 13.9 points on the FHSQ scale (high scale values, less pain), which implies the presence of less pain. In contrast, wearing badly-fitting shoes decreases 9.7 points on the scale, which means an increase in pain.

Based on these results, it is worth noting the importance of evaluating footwear in the medical and podiatric care process, since it is sometimes necessary to prescribe a different shoe size to match the dimension and actual need of each foot, aiming at preventing the appearance of affections and deformities in the feet. This is a key aspect to contribute to improving the health, quality of life and autonomy of the elderly.

Benvenuti et al., ${ }^{18}$ in one of the few epidemiological studies on the incidence of foot pain in the elderly, indicate that women are twice as likely to have foot pain as men. In addition, according to Munro and Steele, ${ }^{19}$ women have more foot problems than men. These findings are consistent with those in our study, which demonstrate that women have more pain, worse foot function, and worse overall foot condition compared to men.

On the other hand, several studies relate the increase of BMI with problems and pain in the feet, increased risk of falls, and worse functional capacity due to mobility-related limitations. ${ }^{20,21}$ In our study we found that BMI and sex are the variables that have an independent effect on the dimensions foot function and general foot condition. Thus, we conclude that increasing BMI worsens the function of the foot, the general foot condition, and the social function of the person, negatively affecting the quality of life of the elderly.
In addition, the results of our study also demonstrate that social function, that is, the person's ability to interact socially, decreases as age increases. For each year-increase in age, there is a 0.7 points-decrease in the scale of Social Function, which denotes a worsening in this dimension. Nevertheless, the general health of the patient, their degree of physical activity and vitality do not seem to be related to the type of shoe.

It is difficult to compare the impact of these results with those of other studies because of differences in criteria and methodological variations, since we have not found any article in the literature that relates quality of life to the use of badly-fitting shoes. This highlights the need to continue research in this line, in order to know how the therapeutic interventions of podiatry and medical professionals can improve foot health and quality of life not only among the elderly but also in the entire population.

\section{Conclusion}

This study provides further evidence that the use of badly-fitting shoes is associated with increased pain in the elderly, resulting in a worsening of the foot-specific quality of life. Hence, the importance of evaluating and advising the elderly on footwear in order to prevent the appearance or development of injuries, relieve foot pain, and improve foot function.

Implementing foot health promotion programs can be a key aspect in the quest to improve the quality of life, autonomy, and well-being of older people.

\section{Resumo}

Impacto do tamanho do calçado em uma amostra de idosos

Introdução: o uso de sapatos com tamanhos inadequados é comum em pessoas idosas e acredita-se resultar em efeito 
negativo sobre a qualidade de vida relacionada à saúde do pé. O objetivo é descrever e comparar o impacto de uma amostra de participantes usando calçados de tamanho adequado e indivíduos com calçados de tamanho inadequado, e as pontuações relacionadas com a saúde do pé e geral.

Método: de uma amostra de 64 participantes, com idade média de 75,3 $\pm 7,9$, de um centro ambulatorial, dados de autorrelato foram registrados e medidas do tamanho dos pés e dos calçados foram determinadas. Os escores foram comparados pelo Foot Health Status Questionnaire, na versão em espanhol, entre os grupos que usavam sapatos de tamanhos corretos e incorretos.

Resultados: o grupo que utilizava sapatos inadequados mostrou pior qualidade de vida relacionada à saúde geral e no pé. Diferenças entre os grupos foram avaliadas utilizando o teste $t$ para amostras independentes, sendo estatisticamente significativas $(\mathrm{p}<0,05)$ para dimensão da dor, função, calçados, saúde geral, do pé e função social. Conclusão: o uso de calçado inadequado tem um impacto negativo significativo sobre a qualidade de vida relacionada à saúde do pé. O grau de impacto negativo parece estar associado com idade, sexo e índice de massa corpórea (IMC).

Palavras-chave: pé, qualidade de vida, deformidades do pé, sapatos, idoso, deformidades do pé.

\section{References}

1. Schwarzkopf R, Perretta DJ, Russell TA, Sheskier SC. Foot and shoe size mismatch in three different New York City populations. J Foot Ankle Surg. 2011; 50(4):391-4.

2. Scott G, Menz HB, Newcombe L. Age-related differences in foot structure and function. Gait Posture. 2007; 26(1):68-75.

3. Menz HB, Auhl M, Ristevski S, Frescos N, Munteanu SE. Evaluation of the accuracy of shoe fitting in older people using three-dimensional foot scanning. J Foot Ankle Res. 2014; 7(1):3.
4. Harrison SJ, Cochrane L, Abboud RJ, Leese GP. Do patients with diabetes wear shoes of the correct size? Int J Clin Pract. 2007; 61(11):1900-4.

5. Nixon BP, Armstrong DG, Wendell C, Vazquez JR, Rabinovich Z, Kimbriel HR, et al. Do US veterans wear appropriately sized shoes?: the Veterans Affairs shoe size selection study. J Am Podiatr Med Assoc. 2006; 96(4):290-2.

6. Shumway-Cook A, Ciol MA, Hoffman J, Dudgeon BJ, Yorkston K, Chan L. Falls in the Medicare population: incidence, associated factors, and impact on health care. Phys Ther. 2009; 89(4):324-32.

7. Najafi B, de Bruin ED, Reeves ND, Armstrong DG, Menz HB. The role of podiatry in the prevention of falls in older people: a JAPMA special issue. J Am Podiatr Med Assoc. 2013; 103(6):452-6.

8. Menz HB, Zammit GV, Munteanu SE. Plantar pressures are higher under callused regions of the foot in older people. Clin Exp Dermatol. 2007; 32(4):375-80.

9. Chaiwanichsiri D, Janchai S, Tantisiriwat N. Foot disorders and falls in older persons. Gerontology. 2009; 55(3):296-302.

10. Scott G, Menz HB, Newcombe L. Age-related differences in foot structure and function. Gait Posture. 2007; 26(1):68-75.

11. Sirera-Vercher MJ, Sáez-Zamora P, Sanz-Amaro MD. Traducción y adaptación transcultural al castellano y al valenciano del Foot Health Status Questionnaire. Rev Esp Cir Ortop Traumatol. 2010; 54(4):211-9.

12. Friends J, Augustine E, Danoff J. A comparison of different assessment techniques for measuring foot and ankle volume in healthy adults. J Am Podiatr Med Assoc. 2008; 98(2):85-94.

13. McInnes AD, Hashmi F, Farndon LJ, Church A, Haley M, Sanger DM, et al. Comparison of shoe-length fit between people with and without diabetic peripheral neuropathy: a case-control study. J Foot Ankle Res. 2012; 5(9)

14. Irving DB, Cook JL, Young MA, Menz HB. Impact of chronic plantar heel pain on health-related quality of life. J Am Podiatr Med Assoc. 2008; 98(4):283-9.

15. Macfarlane RM, Jeffcoate WJ. Factors contributing to the presentation of diabetic foot ulcers. Diabet Med. 1997; 14(10):867-70.

16. Nixon BP, Armstrong DG, Wendell C, Vazquez JR, Rabinovich Z, Kimbriel $\mathrm{HR}$, et al. Do US veterans wear appropriately sized shoes?: the Veterans Affairs shoe size selection study. J Am Podiatr Med Assoc. 2006; 96(4):290-2.

17. Burns SL, Leese GP, McMurdo MET. Older people and ill fitting shoes. Postgrad Med J. 2002; 78(920):344-6.

18. Benvenuti F, Ferrucci L, Guralnik JM, Gangemi S, Baroni A. Foot pain and disability in older persons: an epidemiologic survey. J Am Geriatr Soc. 1995; 43(5):479-84

19. Munro BJ, Steele JR. Foot-care awareness. A survey of persons aged 65 years and older. J Am Podiatr Med Assoc. 1998; 88(5):242-8.

20. Jeon B-J. The effects of obesity on fall efficacy in elderly people. J Phys Ther Sci. 2013; 25(11):1485-9.

21. Turan Turgut S, Içağasığlu A, Selimoğlu E, Şahin P, Yumuşakhuylu Y, Murat S. Musculoskeletal pain and quality of life in obese patients. J Musculoskelet Pain. 2014; 22(1):43-50. 